\begin{tabular}{lccc} 
VERSITA & GOSPODARKA & SUROWCAMI & MINERALNYMI \\
\hline Tom 28 & 2012 & Zeszyt 3 \\
& \multicolumn{2}{c}{ DOI 10.2478/v10269-012-0018-y }
\end{tabular}

\title{
Heurystyczne modele procesów rozdrabniania jako podstawa symulacyjnej optymalizacji ich przebiegu
}

\begin{abstract}
Wprowadzenie
Procesy rozdrabniania w przeróbce surowców mineralnych są podstawowymi procesami, dzięki którym uzyskuje się produkty końcowe lub produkty przygotowane do stosowania procesów wzbogacania lub rozdziału. Modelowanie matematyczne tych procesów musi brać pod uwage dwa podstawowe czynniki wpływające na ich przebieg, tzn. charakterystyki stosowanych maszyn oraz właściwości rozdrabnianego materiału.

W zależności od stosowanych maszyn oraz zakresu (celów) rozdrabniania można wyróżnić dwa sposoby modelowania procesów rozdrabniania:

- opis składu ziarnowego produktu po przejściu materiału przez urządzenie (zakończenie procesu rozdrabniania - podejście statyczne),

— opis składu ziarnowego w trakcie trwania procesu (kinetyka procesu rozdrabniania).

Heurystyczne podejście do budowy modeli rozdrabniania wymaga uzasadnionego logicznie (w mniejszym lub większym stopniu) powiązania wyników rozdrabniania z parametrami pracy (wielkościami technicznymi lub technologicznymi) maszyn lub ich układów. Takie opracowanie modeli pozwoliłoby także na uzasadnione przeprowadzenie symulacji przebiegu procesów rozdrabniania, a nawet wskazanie optymalnych warunków (dobór parametrów techniczno-technologicznych).

Przy tworzeniu modeli opartych na opisie składu ziarnowego produktu warto zwrócić uwagę, że rozważane charakterystyki składu powinny się opierać na funkcjach rozkładów
\end{abstract}

* Prof. dr hab., AGH Akademia Górniczo-Hutnicza, Wydział Górnictwa i Geoinżynierii, Kraków; e-mail: tadeusz.tumidajski@agh.edu.pl 
cenzurowanych lub uciętych (Tumidajski, Saramak 2009), a modele kinetyki rozdrabniania (mielenia) na ogólnych prawach zachowania masy (bilansu składników).

W kolejnych rozdziałach zostaną więc przedstawione ogólne zasady posługiwania się rozkładami cenzurowanymi i uciętymi, a następnie próba powiązania ich parametrów z charakterystykami kruszarek lub przesiewaczy. Zostanie także przedstawiony ogólny model kinetyki mielenia, a także próby konstrukcji funkcji celu, która byłaby podstawą optymalizacji procesów rozdrabniania.

\section{Zastosowanie rozkładów cenzurowanych i uciętych w opisie procesów rozdrabniania i klasyfikacji}

Jest rzeczą naturalną, że skład ziarnowy powinien być opisywany rozkładami zmiennych losowych dla ziaren o wielkościach z przedziału $\left(0, d_{\max }\right\rangle$. Wiele powszechnie używanych rozkładów, np. rozkład Weibulla znany w przeróbce jako wzór Rosina-Rammlera, rozkład logarytmiczno-normalny stosuje się do przedziału wielkości ziaren $(0,+\infty)$. Poprzez modyfikację zmiennych można funkcję gęstości i dystrybuanty rozkładów określonych na przedziale nieskończonym sprowadzić do przedziału $\left(0, d_{\max }\right\rangle$.

Do dalszych rozważań przyjmiemy cztery najczęściej stosowane rozkłady do opisu krzywych składu ziarnowego w wersji cenzurowanej wartością $d_{\max }$ (King 2001).

Niech

$$
u=\frac{d}{d_{\max }}
$$

oraz

$$
w=\frac{u}{1-u}=\frac{\frac{d}{d_{\max }}}{1-\frac{d}{d_{\max }}}=\frac{d}{d_{\max }-d}
$$

gdzie: $\left(0, d_{\max }\right\rangle$.

Określmy zmodyfikowane dystrybuanty rozkładów:

— rozkład potęgowy (wzór Gaudina-Schuhmanna-Andreyeva)

$$
F(d)=1-(u)^{k}=1-\left(\frac{d}{d_{\max }}\right)^{k}
$$

gdzie:

$$
\mathrm{k} \text { - parametr; }
$$


— rozkład Weibulla (wzór Rosina-Rammlera-Bennetta)

$$
F(d)=1-\exp \left(-\left(\frac{w}{w_{63}}, 2\right)^{n}\right)=1-\exp \left(-c\left(\frac{d}{d_{\max }-d}\right)^{n}\right)
$$

gdzie:

$c, n$ - parametry,

$w_{63,2}$ - kwantyl rzędu 63,2;

— rozkład logarytmiczno-normalny

$$
F(d)=G\left(\frac{\ln \left(\frac{w}{w_{50}}\right)}{\sigma}\right)
$$

gdzie:

$$
\begin{aligned}
& G(x)=\frac{1}{\sqrt{2 \pi}} \int_{-0}^{x} e^{\frac{t^{2}}{2}} d t, \\
& \sigma=\frac{1}{2}\left(\ln w_{84}-\ln w_{16}\right), \\
& w_{16}, w_{50}, w_{84}-\text { kwantyle wskazanych rzędów; } \\
& \text { - rozkład logistyczny }
\end{aligned}
$$

$$
F(d)=\frac{1}{1+\left(\frac{w}{w_{50}}\right)^{-\lambda}}=\frac{1}{1+a\left(\frac{d_{\max }}{d}\right)^{\tau}}
$$

gdzie:

$$
\begin{aligned}
& a, \lambda-\text { parametry, } \\
& w_{50}-\text { kwantyl. }
\end{aligned}
$$

Przedstawione wzory określające dystrybuanty rozkładów cenzurowanych zawierają jeden podstawowy parametr $d_{\max }$ oraz - z reguły - dwa parametry nazywane często parametrami kształtu i skali. Jest rzeczą oczywistą, że wartość $d_{\text {max }}$ może być wiązana z gabarytami maszyny (wielkością szczeliny wypustowej, skokiem szczęki ruchomej, wielkością oczka rusztu kruszarki młotkowej itp.), a parametry kształtu i skali z właściwościami materiału, a także charakterystykami maszyn decydujących o krotnościach kruszenia (czasie przebywania materiału w kruszarce, może to być np. częstotliwość wahań szczęki ruchomej). 
Uszczegółowienie wymienionych zależności może być przeprowadzone albo precyzyjną analizą pracy danej maszyny i struktury rozdrabnianego materiału albo eksperymentalnie. Sytuacje prowadzące do uzyskiwania przewagi ziaren drobnych (druga pochodna dystrybuanty rozkładu potęgowego lub Weibulla - dodatnia dla $d \in\left(0, d_{\max }\right\rangle$ lub względnej symetrii udziałów klas drobnych i grubych (rozkłady log-normalny i logistyczny) mogą być pomocne przy konstruowaniu zależności, których postacie mogą być także uzyskiwane metodami doświadczalnymi i związanymi z nimi procedurami obliczeniowymi (Michalewicz 2003; Tumidajski i in. 2009).

Z rozkładami uciętymi w opisie procesów przeróbczych mamy do czynienia przy rozważaniu przebiegu idealnego rozdziału (przesiewania, klasyfikacji, wzbogacania). Jeżeli przyjmiemy, że rozdzielany materiał charakteryzuje dystrybuanta $F(d)$, to idealny rozdział (zwłaszcza na sicie) opisują dystrybuanty:

— dla produktu dolnego

$$
F_{d}(d)=\frac{F(d)}{F\left(d_{s}\right)} \quad d \in\left(0, d_{s}\right)
$$

— dla produktu górnego

$$
F_{g}(d)=\frac{F(d)-F\left(d_{s}\right)}{1-F\left(d_{s}\right)} \quad d \in\left\langle\mathrm{d}_{s}, d_{\max }\right\rangle
$$

gdzie $d_{s}$ jest wymiarem oczka sita przesiewacza (granicą rozdziału).

Tak idealny rozdział materiału przy przesiewaniu można przyjmować tylko w warunkach laboratoryjnych (przy długim czasie przesiewania). W warunkach przemysłowych, przy rozdziale materiału stosuje się tzw. krzywe rozdziału, które określają prawdopodobieństwa przejścia ziarna o wielkości $d$ do produktu górnego lub dolnego. Jeżeli przyjmiemy, że $\varphi(d)$ jest właśnie tym prawdopodobieństwem, to możemy napisać

$$
\begin{gathered}
\left.F_{g}(d)=\int_{0}^{d} \varphi(x) f(x) d x, \quad 0, d_{\max }\right\rangle \\
\left.F_{d}(d)=\int_{0}^{d}(1-\varphi(x)) f(x) d x, \quad 0, d_{\max }\right\rangle
\end{gathered}
$$

gdzie $f(d)$ jest pochodną $F(d)$, czyli funkcją gęstości prawdopodobieństwa zmiennej losowej $D$ dla rozdzielanego materiału. Takie podejście jest powszechnie stosowane w klasyfikacji przepływowej (klasyfikatory zwojowe, hydrocyklony, wirówki itp.), przy czym 
przyjmuje się z reguły, że $\varphi(d)$ ma postać dystrybuanty rozkładu normalnego lub jej przybliżeń (Tumidajski 1997). Dla przesiewania krzywe (funkcje) rozdziału muszą mieć inną postać, uwzględniającą ucięcie rozkładu wyjściowego w $d=d_{S}$, czyli:

- dla produktu górnego

$$
\varphi(d)= \begin{cases}\varphi_{1}(d) & d \in\left(0, d_{s}\right\rangle \\ 1 & d \in\left(d_{s}, d_{\max }\right\rangle\end{cases}
$$

— dla produktu dolnego

$$
\varphi(d)= \begin{cases}1-\varphi_{1}(d) & d \in\left(0, d_{s}\right\rangle \\ 0 & d \in\left(d_{s}, d_{\max }\right\rangle\end{cases}
$$

Zgodnie z ostatnimi wzorami należy wprowadzić poprawki do wzorów (5). Otrzymujemy więc

- dla produktu dolnego

$$
F_{d}(d)=\frac{\int_{0}^{d}\left(1-\varphi_{1}(x)\right) f(x) d x}{\int_{0}^{d_{s}}\left(1-\varphi_{1}(d)\right) f(d) d d} \quad d \in\left(0, d_{s}\right)
$$

— dla produktu górnego

$$
F_{g}(d)=\frac{\int_{d_{s}}^{x} \varphi_{1}(x) f(x) d x-\int_{0}^{d_{s}}\left(1-\varphi_{1}(x)\right) f(d) d d}{1-\int_{0}^{d_{s}}\left(1-\varphi_{1}(d)\right) f(d) d d}
$$

Rozkład wielkości ziaren dla produktu górnego można potraktować jako klasyczny rozkład ucięty ze zniekształceniem (Benjamin, Cornell 1977; Tumidajski 1997), polegającym na przypisaniu wielkości $d_{s}$ nieprzesianej ilości (względnej) ziaren o wielkościach mniejszych od $d_{s}$.

Zaprezentowane krzywe składu ziarnowego mogą być podstawą modeli matematycznych procesów rozdrabniania i klasyfikacji, jeżeli ich parametry zostaną uzależnione od charakterystyk technicznych i technologicznych maszyn czy procesów. 


\section{Parametry techniczne i technologiczne kruszarek}

Z punktu widzenia projektanta układów rozdrabniania i klasyfikacji modele matematyczne pracy maszyn stosowane także w procedurach symulacyjnych powinny pozwolić na określenie najlepszych (najlepiej dostosowanych do realizacji zadanych celów pracy układu) parametrów technicznych urządzeń, związanych także z ich wydajnością.

Do podstawowych urządzeń rozdrabniających stosowanych w warunkach przemysłowych należą kruszarki szczękowe, stożkowe i młotkowe, prasy walcowe i młyny. Najważniejszymi parametrami konstrukcyjno-eksploatacyjnymi kruszarek szczękowych są: szerokość szczeliny wylotowej, skok szczęki ruchomej, profil poprzeczny i podłużny płyt, prędkość obrotowa wału mimośrodowego (częstotliwość wahań szczęki ruchomej), kąt nachylenia płyty rozporowej. W warunkach przemysłowych regulowane są tylko pierwsze dwa parametry, pozostałe ustalane są projektowo dla danego typoszeregu kruszarki (Gawenda 2010).

Generalnie najważniejszymi parametrami kruszarki stożkowej są: kąt uchwytu (profil szczęki), prędkość obrotowa głowicy oraz wielkość szczeliny wylotowej i wlotowej mające także wpływ na wydajność.

Skład ziarnowy produktu kruszarek młotkowych, a także wydajność zależy od liczby obrotów wirnika, jego wymiarów, kształtu i masy młotków, a także wymaganego stopnia rozdrobnienia (wielkości otworów stosowanego rusztu).

Parametrami pracy wysokociśnieniowych pras walcowych, które mogą być regulowane przez operatora są: ciśnienie robocze oraz prędkość obrotowa walców. Kluczowym jest ciśnienie robocze, które (przy jego wzroście) zwiększa stopień rozdrobnienia materiału (zmniejsza szerokość szczeliny wylotowej), ale zmniejsza wydajność urządzenia (Naziemiec, Saramak 2009; Saramak 2011a, b). Wydajność prasy walcowej zależy także od prędkości obrotowej walców oraz gęstości sprasowanego produktu rozdrabniania.

Młyny zaliczane są do najmniej sprawnych i najbardziej energochłonnych urządzeń rozdrabniających i dlatego przy projektowaniu układów rozdrabniania trzeba zakładać jak największy stopień rozdrobnienia $\mathrm{w}$ kruszarkach poprzedzających mielenie. Właściwie dobrane parametry technologiczne młyna decydują o jego efektywności, tzn. składzie ziarnowym i wydajności. Należy do nich zaliczyć: względną częstość obrotów młyna, względne zapełnienie młyna mielnikami, kształt i wielkość mielników, profil wykładzin młyna, wypełnienie młyna nadawą, właściwości nadawy.

\section{Zasady optymalizacji wyników procesów rozdrabniania}

Przedstawiona do tej pory koncepcja tworzenia modeli pracy maszyn przeróbczych i ich układów zakłada uzależnienie parametrów krzywych składu ziarnowego produktów oraz krzywych rozdziału od parametrów techniczno-technologicznych urządzeń rozdrabniających. 
Jeżeli oznaczymy przez $d_{\max }, n, c$ - parametry wzorów opisujących krzywe składu produktów, a przez $r, s$ - parametry maszyn, to możemy zapisać ogólnie

$$
F(d)-=F(d ; r, s)=F\left(d ; d_{\max (r s)}, n(r, s), c(r, s)\right)
$$

Jeżeli mamy do czynienia z produkcją kruszyw mineralnych (rys. 1) można zaproponować następującą funkcję celu, która będzie stanowić podstawę optymalizacji (maksymalizacja wartości). Jest to uogólnienie funkcji celu zaprezentowanej w pracy (Svedensten, Evertsson 2005).

$Z=\sum_{\downarrow}(n=1)^{\uparrow} m \equiv \sum_{\downarrow}(i=1)^{\uparrow} p \equiv\left(C_{\downarrow} h-\mu_{\downarrow} h i \frac{\downarrow i+(\downarrow g o d z, i)}{Q_{\downarrow} i}-(\downarrow p o c z) Q_{\downarrow} i \gamma_{\downarrow} h i\right.$

gdzie:

$C_{h} \quad$ - cena produktu będącego $h$-tą klasą (przy przyjętym podziale materiału na klasy), której wychód wyznacza się na podstawie równania (9),

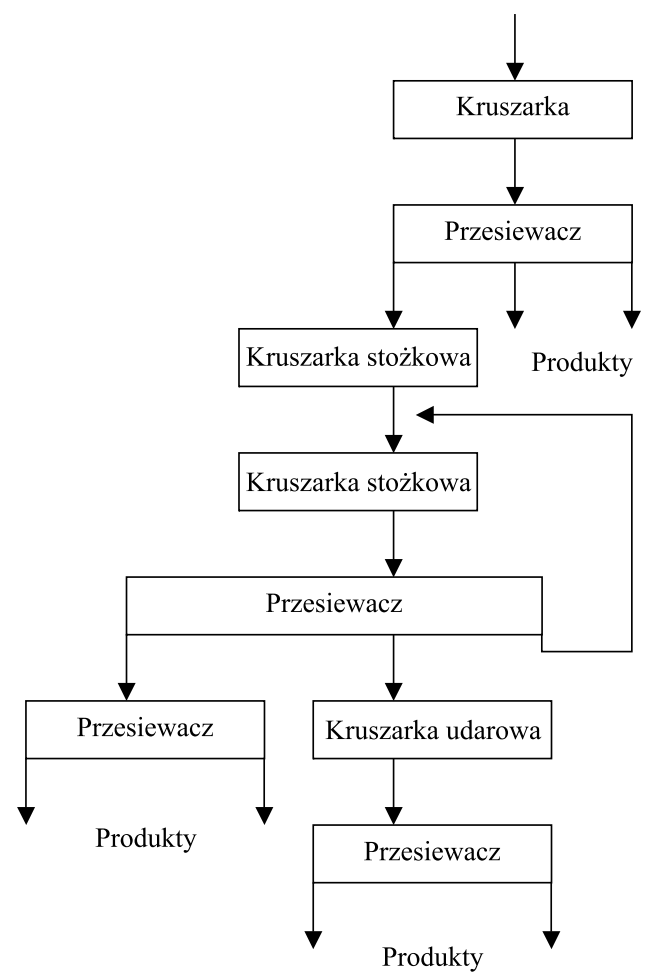

Rys. 1. Uproszczony szeregowy schemat technologiczny produkcji kruszyw bazaltowych Źródło: Nowak, Gawenda 2006

Fig. 1. Simplified serial technological scheme of basalt rock materials production 
$\kappa_{\text {godz, } i}-$ koszt stały na godzinę $\mathrm{w} i$-tej operacji,

$\kappa_{i} \quad-$ koszt stały $\mathrm{w} i$-tej operacji,

$\kappa_{\text {pocz }}-$ koszt początkowy,

$\mu_{h} \quad-$ mnożnik korekcyjny,

$Q \quad$ - wydajność w $i$-tej operacji [Mg/godz.],

$\gamma_{h i} \quad-$ wychód $h$-tej klasy w $i$-tej operacji.

Wyprecyzowanie poszczególnych równań krzywych składu ziarnowego wymaga szczegółowej analizy pracy urządzeń lub przeprowadzenia badań empirycznych. Proponowana metoda modelowania nie ma charakteru ogólnego. Rozważmy możliwy schemat przygotowania nadawy rud (np. miedzi) do procesów wzbogacania (flotacji) (rys. 2).

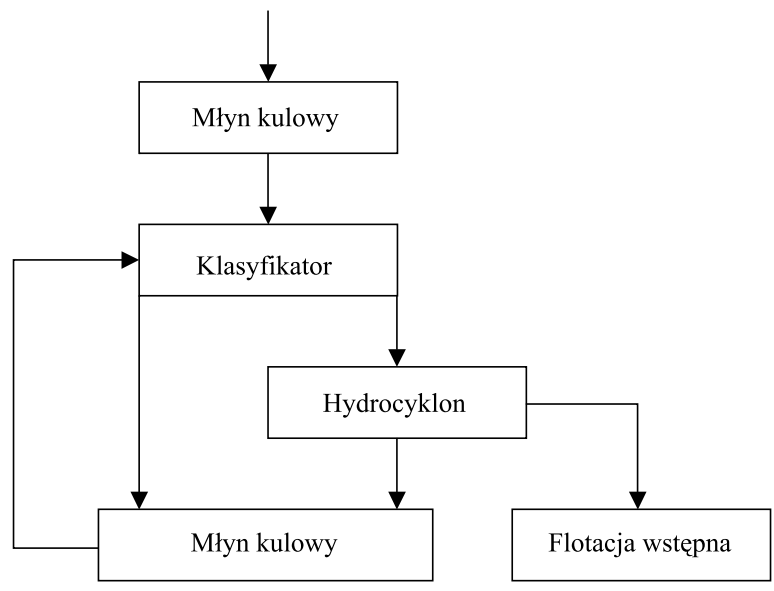

Rys. 2. Przykładowy układ przygotowania rud do flotacji Źródło: Opracowanie własne

Fig. 2. Example of flotation ore preparation system

Najczęściej stosowanym modelem pracy młyna kulowego jest model kinetyki

$$
\frac{d m_{i}}{d t}=-S_{i} m_{i}+\sum_{j=1}^{i} b_{i j} s_{j} m_{j}, \quad \text { dla } i=1,2, \ldots, n
$$

gdzie $m_{i}, S_{i}, b_{i j}$ to odpowiednio masa materiału $i$-tej klasy (przechodzącej przez sito), wartość funkcji selekcji oraz wartość funkcji rozdrabniania dla $i$-tej klasy, gdy ziarna na kruszarce pochodzą z $j$-tej klasy (Prasher 1987).

Parametry techniczne młyna (za wyjątkiem częstości obrotów) praktycznie nie wpływają na skład ziarnowy produktu. O składzie ziarnowym decyduja parametry technologiczne: gęstość mętów, wydajność młyna (przerób), ilość i rodzaj mielników i ich wpływ można określać tylko empirycznie w powiązaniu z właściwościami materiału rozdrobnionego. 
Celem pracy prezentowanego układu jest uzyskanie drobnouziarnionego przelewu hydrocyklonu kierowanego do flotacji. Funkcją celu może być uzyskanie odpowiedniego stopnia uwolnienia minerałów użytecznych (odpowiednich klas ziarnowych). Rolę współczynników $C_{h}$ (wzór 10) mogą spełniać stopnie uwolnienia (na podstawie rozpoznania rudy), przy zmienionej postaci funkcji celu.

\section{Uwagi końcowe}

Zarysowane dwie drogi pozyskiwania modeli matematycznych procesów rozdrabniania tworzą różne możliwości ich wykorzystania (prognoza, symulacja, optymalizacja). Dokładna analiza pracy urządzeń rozdrabniających powinna dać możliwość określenia potrzebnych zależności między parametrami wzorów a parametrami technicznymi maszyn. Procedury symulacyjno-optymalizacyjne można realizować za pomocą algorytmów genetycznych (Goldberg 1998; Michalewicz 2003) lub innych procedur obliczeniowych. Dalsze badania będą polegać także na eksperymentalnym poszukiwaniu potrzebnych zależności.

Artykuł został opracowany w ramach projektu pracy statutowej nr 11.11.100.276.

\section{LITERATURA}

B enja min J.R., Cornell C.A., 1977 - Rachunek prawdopodobieństwa, statystyka matematyczna i teoria decyzji dla inżynierów. WNT, Warszawa.

Gawenda T., 2010 - Rozdrabnianie surowców skalnych w kruszarce szczękowej typu L44.41. Surowce i Maszyny Budowlane, nr 2, pp. 37-42, Wydawnictwo BMP, Racibórz 10.

Goldberg D.E., 1998 - Algorytmy genetyczne i ich zastosowania. Wydawnictwa Naukowo-Techniczne, Warszawa.

K ing R.P., 2001 - Modeling and Simulation of Mineral Processing Systems. Butterworth Heinemann, Boston Oxford Auckland Johannesburg Melbourne New Delhi.

Michalewicz Z., 2003 - Algorytmy genetyczne + struktury danych = program ewolucyjne. Wydawnictwa Naukowo-Techniczne, Warszawa.

Na zi e mi e c Z., S a ra mak D., 2009 - Analiza zmian obciążenia materiału w strefie zgniotu pras walcowych. Górnictwo i Geoinżynieria, vol. 33, z. 4.

Now a k A., G a w en d a T., 2006 - Analiza porównawcza kruszarek w wielostadialnych układach rozdrabniania skał bazaltowych. Górnictwo i Geoinżynieria, z. 3/1, pp. 267-278, Kraków.

Pras he r C.L., 1987 - Crushing and Grinding Process Handbook. John Wiley \& Sons Ltd.

S a r mak D., 2011a - Technological Issues of High-Pressure Grinding Rolls Operation in Ore Comminution Processes. Archives of Mining Sciences, vol. 56, iss. 3, Wyd. IMG PAN.

S a ra mak D., 2011b - The influence of chosen ore properties on efficiency of HPGR-based grinding circuits Gospodarka Surowcami Mineralnymi, z. 4, pp. 33-44.

Svedensten P., Evertss on C.M., 2005 - Crushing plant optimisation by means of a genetic evolutionary algorithm. Minerals Engineering, vol. 18, pp. 473-479.

Tumidajski i in. 2009 - Tumidajski T., Foszcz D., Jamróz D., Niedoba T., Saramak D., 2009 Niestandardowe metody statystyczne i obliczeniowe w opisie procesów przeróbki surowców mineralnych. Wyd. IGSMiE PAN, Katowice. 
Tumidajski T., 1997 - Stochastyczna analiza własności materiałów uziarnionych i procesów ich rozdziału. Wydawnictwo AGH, Rozp. M. nr 57, Kraków.

Tumidajski T., Saramak D., 2009 - Metody i modele statystyki matematycznej w przeróbce surowców mineralnych. Wydawnictwa AGH, Kraków.

HEURYSTYCZNE MODELE PROCESÓW ROZDRABNIANIA JAKO PODSTAWA SYMULACYJNEJ OPTYMALIZACJI ICH PRZEBIEGU

\section{Słowa kluczowe}

Cenzurowane krzywe składu ziarnowego, modele procesów rozdrabniania, symulacyjne określenie optimum

\section{Streszczenie}

Modelowanie matematyczne procesów przeróbczych jest zadaniem bardzo złożonym ze względu na losowy charakter rozdrabnianych materiałów, pozwalający jednak na zastosowanie ogólnie obowiązujących praw zachowania i transportu mas. Podstawową metodą opisu efektów procesów rozdrabniania jest określenie krzywych składu ziarnowego produktów. W artykule przedstawiono koncepcję stosowania cenzurowanych rozkładów wielkości ziarna, tzn. wzorów na dystrybuanty rozkładów: potęgowego, Weibulla, logarytmiczno-normalnego i logistycznego jako podstawy opisu prac kruszarek (wzory 1, 2, 3, 4). Cenzurowanie rozkładów realizowane jest poprzez przyjęcie rozmiaru maksymalnego ziarna $d_{\max }$, a kształt ich dystrybuant zależy od parametrów kształtu i skali. Powiązanie parametrów technicznych urządzeń rozdrabniających z parametrami wzorów określających dystrybuanty produktów pozwala na stworzenie satysfakcjonujących modeli procesów rozdrabniania. Po zastosowaniu uogólnionych krzywych rozdziału możliwy jest opis procesów przesiewania (wzory 6a i 6b), a w dalszej kolejności układów procesów rozdrabniania. Optymalizację procesów produkcji kruszyw można oprzeć na wprowadzeniu funkcji celu określającej zysk w zależności od ilości poszczególnych sortymentów. W przypadku analizy układów rozdrabniania (wzór 10) w przygotowaniu nadawy do procesów wzbogacania, funkcję celu należałoby oprzeć na poziomach odsłonięcia minerałów użytecznych w klasach. W artykule pokazano możliwość symulacji przebiegu procesów rozdrabniania, prowadzącej do określenia warunków optymalnych pracy układów złożonych z procesów rozdrabniania i przesiewania. Zwrócono uwagę na konieczność budowy empirycznych modeli procesów mielenia, które będą stanowiły uzupełnienie modeli wynikających z heurystycznej analizy zjawisk. Omówiono także elementarne zasady doboru postaci modeli oraz ich modyfikacji polegające na uzasadnieniu zależności parametrów rozkładu od podstawowych parametrów technicznych maszyn oraz właściwości rozdrabnianych materiałów. Artykuł jest wstępem do zamierzonych szerszych badań uogólnionego podejścia do powiązania właściwości materiałów uziarnionych z efektami rozdrabniania.

HEURISTIC MODELS OF COMMINUTION PROCESSES AS THE BASIC OF SIMULATIVE OPTIMISATION OF THEIR COURSE

$$
\text { Key words }
$$

Censored particle size curves, models of comminution processes, simulative determination of optimal point

\section{Abstract}

The mathematical modeling of mineral processing is a very complex task because of random character of comminuted materials. However, it allows applying of standard laws of mass preservation and mass transport. The basic method of description of comminution processes is determination of particles size distribution curves for products. In the paper, the concept of applying so-called censored distribution functions was presented, 
what means equations of exponential, Weibull, log-norm and logistic distribution functions as the basis of crushers work description (formulas 1, 2, 3 and 4). The censoring of distribution functions is being realized through acceptation of maximum particle size $\mathrm{d}_{\max }$ and the shape of them depends on shape and scale parameters. The joining of technical parameters of comminuting devices with parameters of equations describing distribution functions of products allows creating of satisfying models of comminution processes. After application of general forms of separation curves the description of sieving processes is possible (equations $6 \mathrm{a}$ and $6 \mathrm{~b}$ ) and then also of comminution systems. The optimization of aggregates production may be based on introduction of goal function determining profit dependably on amount of individual assortments. In case of analysis of comminution systems (formulae 10) in preparation of feed to beneficiation the goal function should be based on levels of useful minerals exposure in individual fractions. The paper shows the possibility of simulation of comminution processes course leading to determination of optimal conditions of systems containing comminution and sieving processes. Furthermore, the necessity of creation of empirical models for grinding processes was shown as they would be the compensation of models being result of heuristic analysis of phenomena. Also, the elementary rules of selection of models forms and their modifications based on justification of relations between distribution function parameters and basic technical parameters of devices as well characteristics of comminuted materials were discussed. The paper is the introduction to further research of general approach to joining grained materials characteristics with comminution effects. 
